\title{
Star tracker and vision systems performance in a high radiation environment
}

\author{
Jørgensen, John Leif; Riis, Troels; Betto, Maurizio
}

Published in:

Aerospace Conference, 1999. Proceedings. 1999 IEEE

Link to article, DOI:

10.1109/AERO.1999.793149

Publication date:

1999

Document Version

Publisher's PDF, also known as Version of record

Link back to DTU Orbit

Citation (APA):

Jørgensen, J. L., Riis, T., \& Betto, M. (1999). Star tracker and vision systems performance in a high radiation environment. In Aerospace Conference, 1999. Proceedings. 1999 IEEE (Vol. 2). IEEE.

https://doi.org/10.1109/AERO.1999.793149

\section{General rights}

Copyright and moral rights for the publications made accessible in the public portal are retained by the authors and/or other copyright owners and it is a condition of accessing publications that users recognise and abide by the legal requirements associated with these rights.

- Users may download and print one copy of any publication from the public portal for the purpose of private study or research.

- You may not further distribute the material or use it for any profit-making activity or commercial gain

- You may freely distribute the URL identifying the publication in the public portal

If you believe that this document breaches copyright please contact us providing details, and we will remove access to the work immediately and investigate your claim 


\section{Star Tracker and Vision Systems Performance in a High Radiation Environment}

\author{
John L. Jørgensen \\ Technical University of Denmark \\ Department of Automation \\ Bld. 327 \\ 2800 Lyngby \\ Denmark \\ +45253448 \\ ili@iau.dtu.dk
}

\author{
Troels Riis \\ Technical University of Denmark \\ Department of Automation \\ Bld. 327 \\ 2800 Lyngby \\ Denmark \\ +45253439 \\ tr@iau.dtu.dk
}

\author{
Maurizio Betto \\ Technical University of Denmark \\ Department of Automation \\ Bld. 327 \\ 2800 Lyngby \\ Denmark \\ +45253439 \\ mbe@iau.dtu.dk
}

Abstract- A part of the payload of the second Ariane 5 prototype vehicle to be launched by Arianespace, was a small technology demonstration satellite. On October $30^{\text {th }}, 1997$, this test satellite, dubbed Teamsat, was launched into Geostationary Transfer Orbit and would as such pass the Van Allen radiation belts twice per orbit.

One of the experiments onboard Teamsat was the so-called Autonomous Vision System (AVS). The AVS instrument is a fully autonomous star tracker with several advanced features for non-stellar object detection and tracking, real-time image compression and transmission. The objectives for the AVS in Teamsat were to test these functions, to validate their autonomous operation in space, and to assess the operational constraints of a high radiation environment on such processes. This paper describes the AVS experiment, and the radiation flux experienced onboard TEAMSAT. This overview is followed by examples of the radiation impact on the AVS instrument flown onboard the TEAMSAT, and finally the operations of the various countermeasures are discussed.

\section{TABLE OF CONTENTS}

1. The ARIANe 502 and Teamsat

2. The AVS Instrument BuILding Blocks AND SW FUNCTIONALITY.

3. Physical Layout. Location ON MAQSAT-H.

4. PlanNED AND ACHIEVED ORBIT.

5. LIFETIME DOSE ASSESSMENTS AND THE RADIATION EFFECTS.

6. DYNAMIC EFFECTS FROM RADIATION.

7. RAD-EFFECTS WORK AROUND AND APPLICABILITY.

8. CONCLUSION.

9. REFERENCES.

10. BIOGRAPHY.

\section{THE ARIANE 502 AND TEAMSAT}

The new European heavy lift launcher Ariane 5 has, with its lift capacity of more than 5 tons to Geostationary Transfer
Orbit (GTO), primarily been designed to inject large satellites into GTO or alternatively some 20 tons to Low Earth Orbit, e.g. parts for the space station. After the ill fated first qualification flight, A501, that was to lift the Cluster

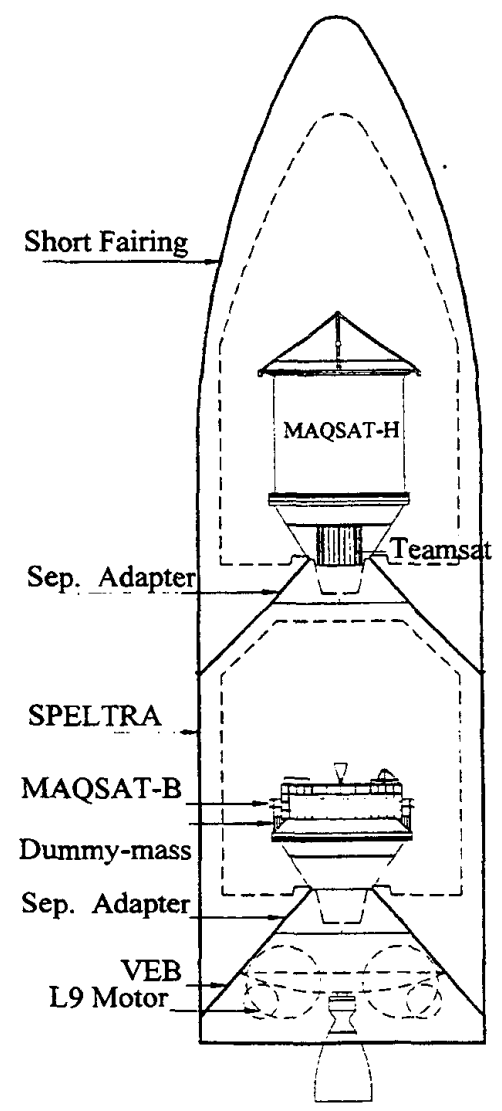

Figure 1: Teamsat inside the A502 fairing showing the two dummy payloads Maqsat-B and $\mathrm{H}$, and the location of the Teamsat. 
satellites to the magneto-helio-pause but was to be brought to self-destruction only 39 seconds after lift-off, it was decided only to launch a dummy payload to test the various functions of the separation, attitude adjustments and depletion burn mechanisms.

One of the benefits of a heavy lift launcher, is the possibility to insert more than one satellite per launcher. To verify this operation two dummy-payloads of approximately equal size and mass, the Maqsat-B (Bas (French) = Lower) and the Maqsat-H (Haut (French) = upper), were fitted under the

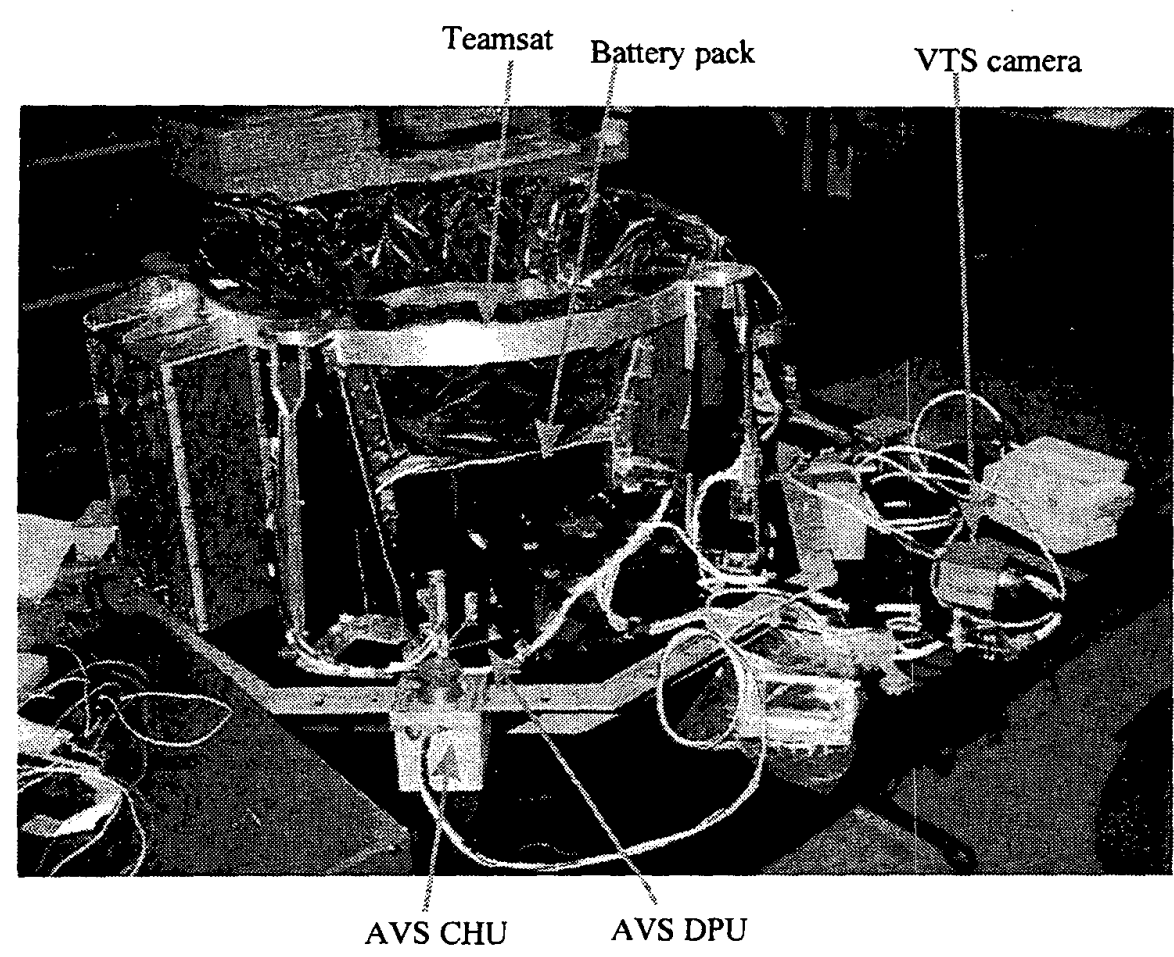

Figure 2: The Teamsat during integration. The CHU is attached to the DPU for system test. fairing of the A502. This configuration is shown in figure 1. In order to be able to verify the tip-off speed and rotation state after separation, Maqsat-H was painted with a distinctive pattern that enabled determination of the rotation state from ground.

The masses of both dummy-satellites were above 2 tons, in order to provide sufficient ballast for the launcher. ESTEC, a technical facility of the European Space Agency, ESA, applied for, and got approved that part of the mass of the Maqsat- $H$ could be used for a technological demonstration sub-payload. The objectives of ESTEC were twofold. Firstly, to get practical experience with a Better-FasterCheaper type mission. And secondly, to provide space departments of European universities and companies with an opportunity to get advanced technologies and equipment tested in space.

The result of this effort was Teamsat. This sub-payload, weighing $350 \mathrm{~kg}$ was to be developed, assembled, tested and operationally verified in precisely 1 year, all at marginal cost. A thorough description of the management and technical effort leading to this achievement is given in reference 1.

Figure 2, shows a photo respectively of Teamsat and its instrumentation.

The payload was powered by two battery-blocks visible in the center, surrounded by the various equipment and instruments. The satellite was solely powered by battery power effectively limiting the operational lifetime to 4 days at nominal operation of the instruments.

Table 1: The instruments of Temasat.

\begin{tabular}{|l|l|l|l|}
\hline Experiment name & PI Organization and Country & Primary objectives & Sensors \\
\hline FIPEX & $\begin{array}{l}\text { University of Stuttgart, } \\
\text { Germany }\end{array}$ & $\begin{array}{l}\text { Atomic Oxygen conc. below } \\
1000 \mathrm{~km}\end{array}$ & $\begin{array}{l}5 \text { high temperature Oxygen } \\
\text { sensors for 4B coverage. }\end{array}$ \\
\hline VTS & $\begin{array}{l}\text { MMS Bristol, UK IMEC \& } \\
\text { OIP, Belgium }\end{array}$ & $\begin{array}{l}\text { Near real-time imaging and } \\
\text { compression }\end{array}$ & $\begin{array}{l}3 \text { APS sensor based cameras and } \\
\text { a compression unit }\end{array}$ \\
\hline ODD & ESTEC, NL & $\begin{array}{l}\text { Ground based orbit and } \\
\text { attitude measurements }\end{array}$ & $\begin{array}{l}\text { Characteristic pattern painted on } \\
\text { Maqsat-H }\end{array}$ \\
\hline YES & ESTEC, NL & $\begin{array}{l}\text { Detachable 35km-tethered } \\
\text { probe. }\end{array}$ & $\begin{array}{l}\text { GPS, Sun sensor, Radiation } \\
\text { detectors and Data processor }\end{array}$ \\
\hline AVS & LAU/DTU, DK & $\begin{array}{l}\text { Autonomous Attitude and } \\
\text { non-stellar object detection } \\
\text { and tracking }\end{array}$ & $\begin{array}{l}\text { CCD-based camera head and } \\
\text { powerful processor with } \\
\text { onboard star-catalogue }\end{array}$ \\
\hline
\end{tabular}


The five experiments/instruments that were finally integrated in Teamsat were FIPEX, VTS, ODD, YES and the AVS. Table 1 above lists key features, functions and results for each instrument.

The spacecraft bus, TM-encoder, TC-decoders, RF-link, Batteries, power distribution unit and hamess were all designed, integrated and tested by ESTEC.

The full process, from concept definition of the satellite to integration into the launcher took just under one year. A thorough description of the mission, its experiments and the data obtained may be found at:

\section{http://www.estec.esa.nl/teamsat}

\section{THE AVS INSTRUMENT BUILDING BLOCKS AND SW FUNCTIONALITY.}

The AVS is basically a second-generation star tracker with several additional features. The unit consists of two separate units, a Camera Head Unit (CHU) and a Data Processing Unit (DPU). The reasons for this division are, that the

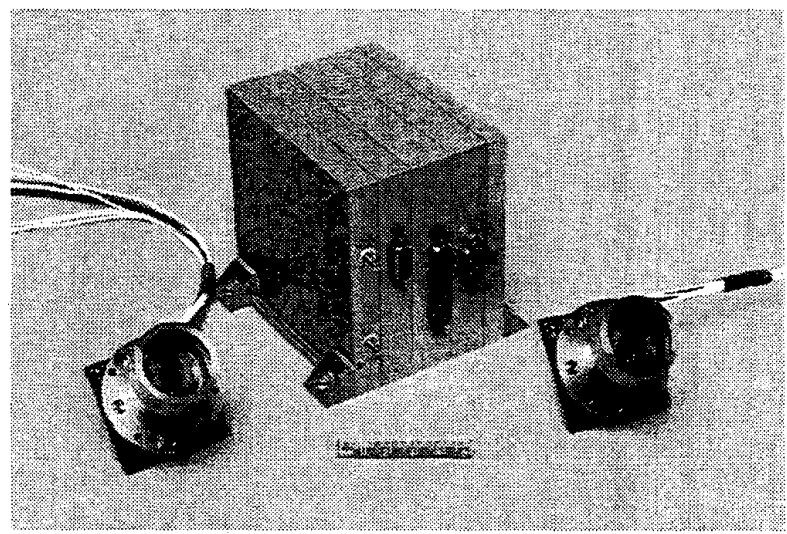

Figure 3: The AVS shown with two CHU's

compact and low power CHU may be placed close to the instrument placing the most stringent attitude accuracy requirement on the satellite. The small DPU that may drive from one to four CHU's may then be placed in a convenient place elsewhere on the satellite bus up to $20 \mathrm{~m}$ away from the CHU's.

Figure 3, shows a photo of a DPU and two CHU's, and figure 4 shows a picture of a CHU with a reference cube. In the Teamsat configuration the DPU was equipped with one CHU. The CHU is based on a commercial Sony CCD chip where the Hyper-Had technology, apart from yielding high uniformity and fill factor, also provides for a relatively high radiation tolerance (Full operation after 10KRad @ 0C). Apart from the $\mathrm{CCD}$, the CHU contains the CCD support chips, level converters and line drive electronics. It is equipped with a high precision and high-speed lens, specially designed and manufactured to optimize the centroiding process, a key process for star tracker operations. The lens provides for a field of view of $21.4 \mathrm{E}$ by $16 \mathrm{E}$. The $\mathrm{CHU}$ shown on figure 4 is encapsulated in a thick Titanium housing to provide additional radiation shielding for the $\mathrm{CCD}$ (the drive electronics operates nominally after more than $80 \mathrm{KRad}$ ).

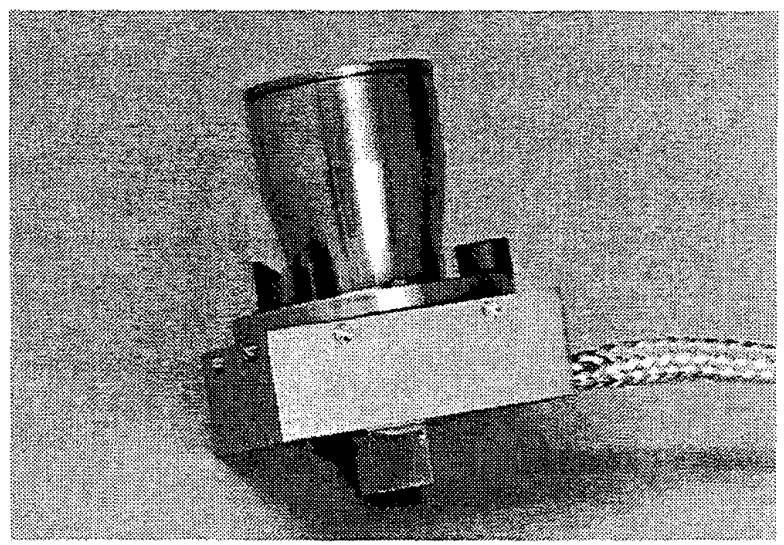

Figure 4: $\mathrm{CHU}$ with reference cube

One of the objectives of the AVS was to obtain performance data for the star tracker operation under high radiation flux conditions. In order to obtain a realistic lifetime dose for the CCD under the 4-days operation to be expected before battery depletion, the backside of the CHU, which was directly exposed to space, was thinned to thickness equivalent of $1.5 \mathrm{~mm}$ aluminum.

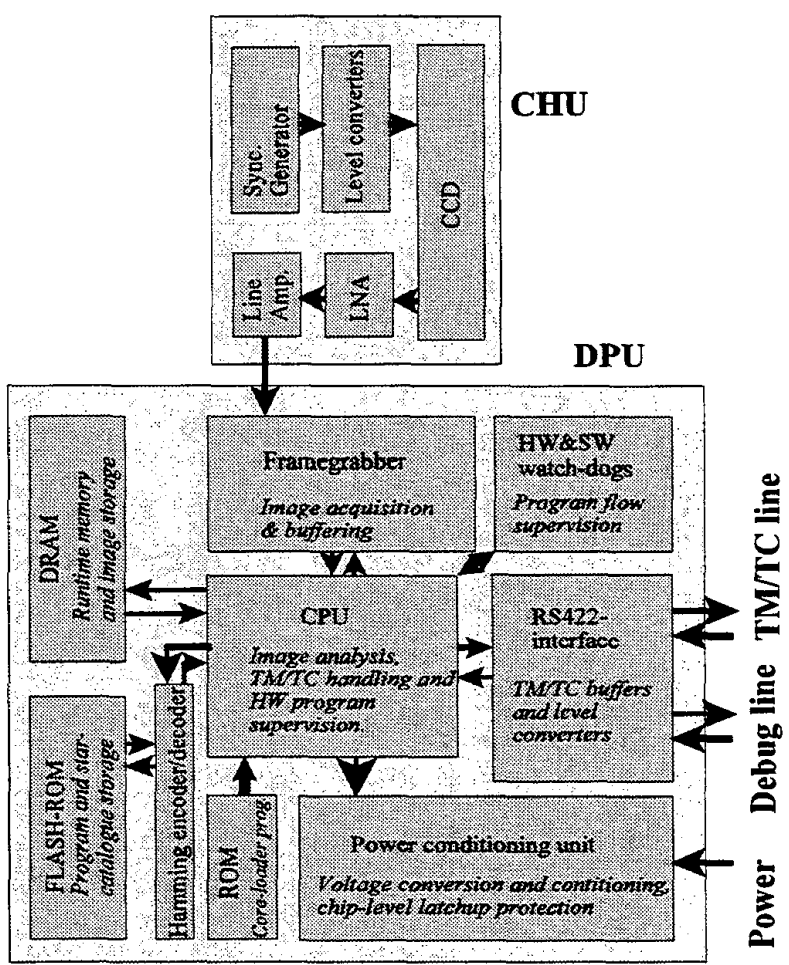

Figure 5: Block diagram of the AVS

To minimize the impact of sunlight reflections from the surface of Teamsat into the lens, the $\mathrm{CHU}$ was equipped with 
a $5 \mathrm{~cm}$ long stray light suppression baffle. A baffle of $5 \mathrm{~cm}$ will not provide sufficient suppression of direct sunlight, but unfortunately, Arianespace would not allow a larger baffle. Hence, blinding by sunlight was to be expected approximately $35 \%$ of the time provided nominal orbit and attitude. The functional blocks of the AVS may be seen at figure 5 .

The DPU consists of a powerful, AMD486 based, microprocessor unit with 4Mbytes of RAM, 4Mbytes of hamming-code protected FLASH-RAM, a frame grabber and an $\mathrm{I} O \mathrm{O}$ interface unit driving two RS422 communication lines. The unit is powered from a $28 \mathrm{~V}$ unregulated power-line.

The program and the star catalogue are stored in the 2 bit detection 1bit correction Hamming-code protected FLASH-memory.

All images received from the $\mathrm{CHU}$ are passed to the autonomous star tracker system algorithm of the DPU. The algorithm starts out by sifting the image for all objects brighter than a threshold value. These objects are then centroided, and the $20-40$ brightest centroids are passed to a search engine that matches the image with the onboard 12.000-star catalogue. When a good match is established, all centroids are matched to the star catalogue.

The main objective of matching all centroids to the star catalogue is to improve the accuracy. Typically the accuracy improves a factor 5 to approximately 0.7 arcsecond $1 \mathrm{~F}$. However, the matching of the full set has additional benefits: It provides extremely robust mean to verify the correctness of the measured attitude, and it automatically detects non-stellar objects. Provided the sensitivity of the $\mathrm{CHU}$ is calibrated relatively to the star catalogue, centroids that do not match any object in the star catalogue must originate in non-stellar objects, as galaxies, ionizing radiation effects, asteroids or other satellites. The AVS autonomously detects such objects and attach a list of the brighter one to each attitude. In order to enable monitoring of the effects from ionizing radiation, especially on the CCD, the AVS is equipped with a real-time imaging function. Images may be compressed by one of several methods, depending on which property is under study. As demonstrated below, this feature proved very powerful to establish the impact of various effects. The compression standards implemented were, raw (uncompressed), centroids, region-of-interest, or JPEG with a selectable compression ratio (from 1-100). Because image data will put a heavy load on the TM-channel, images may not be transmitted real-time. E.g. A raw image took more than 150 sec to transmit. Hence the AVS is equipped with a user-selectable auto-imaging mode: While full attitude and non-stellar object detection are maintained, a new image is stored and compressed whenever transmission of the previous image compressed is completed.

Apart from these features, the AVS maintained autonomous control of system parameters as camera gain, detection threshold, Hamming-code bit-washing procedures and various code- and data-protection functions. A thorough description of the instrument is given in [2].

\section{Physical Layout. LOCATION ON MAQSAT-H}

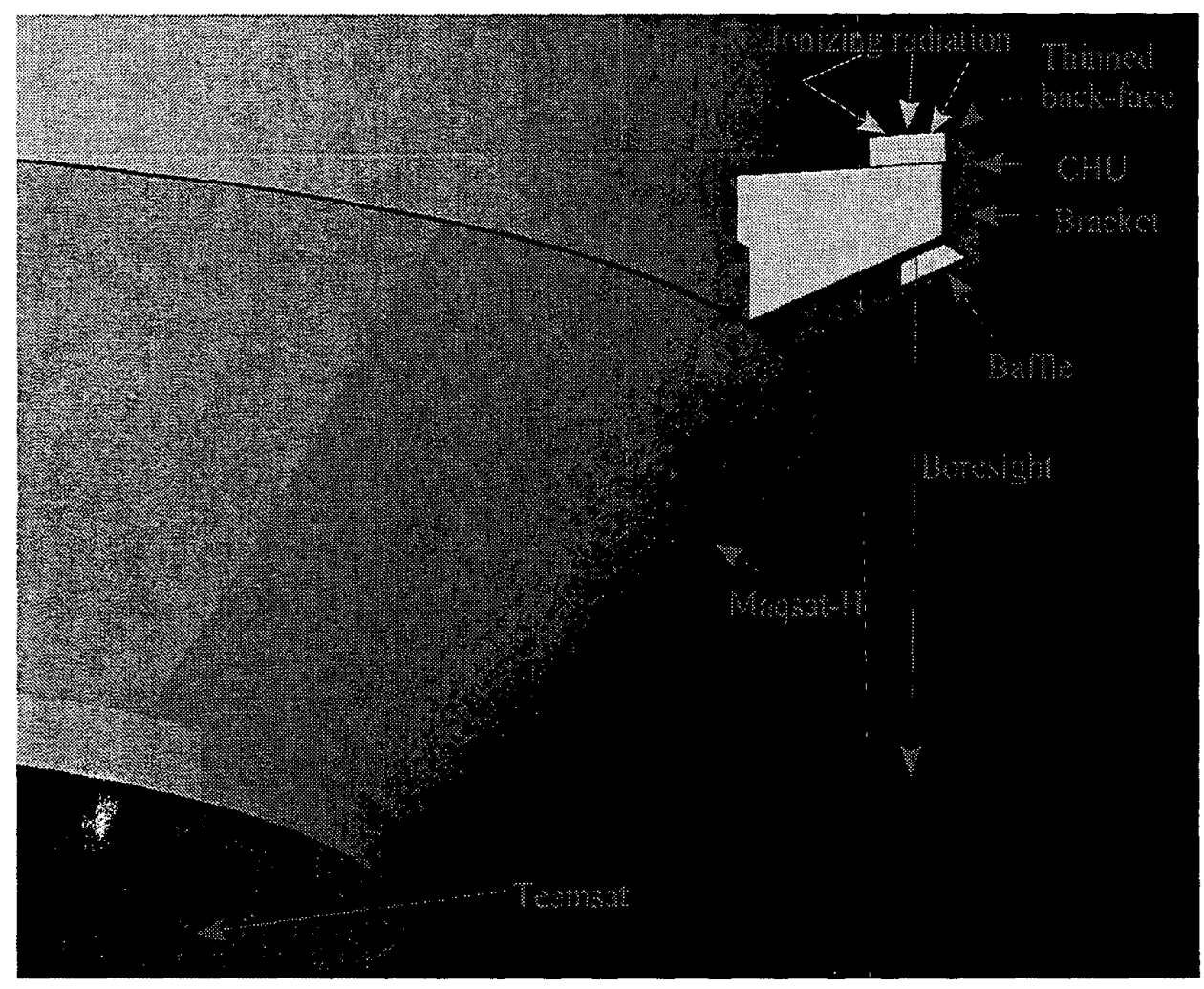

Figure 6: The CHU location
The DPU location inside Teamsat may be inferred from figure 2 . The combined wall thickness of Teamsat and MAQSAT-H provides for a quite effective shielding of all equipment inside the Teamsat structure. The estimated equivalent shielding of equipment inside Teamsat is $30 \mathrm{~mm} \mathrm{Al}$. The $\mathrm{CHU}$ and baffle assembly was mounted on a small bracket close to the separation adapter of MAQSAT- $H$, as shown in figure 6.

This location was selected, because the nominal spin-rate of Teamsat about the symmetry axis was quite high, because this location minimized the amount of spacecraft appendages visible from the $\mathrm{CHU}$, and because the boresight should point away from the sun in the nominal orbit. 


\section{Proton Flux $(\mathrm{E}>10 \mathrm{MeV})$}

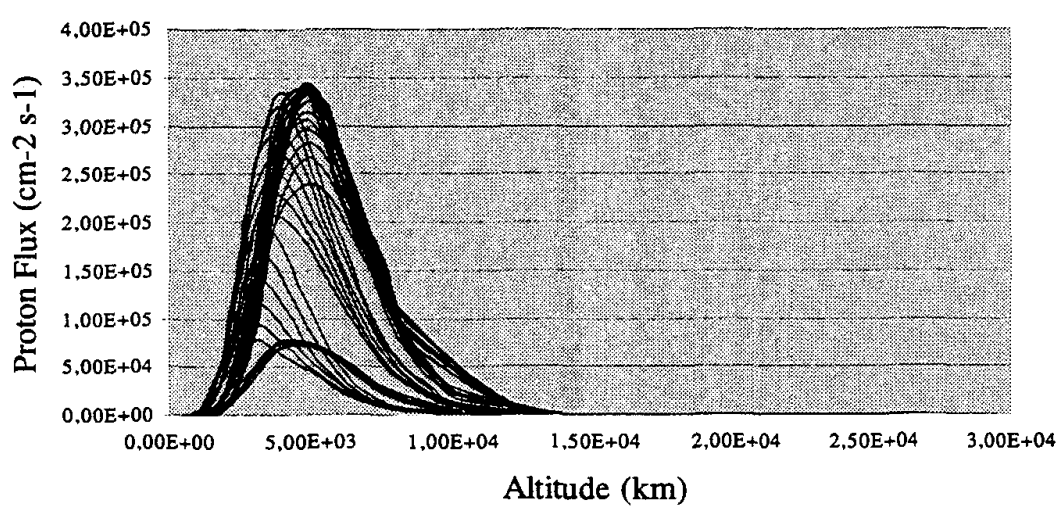

Figure 7: Trapped proton flux

\section{Electron Flux $(E>1 \mathrm{MeV})$}

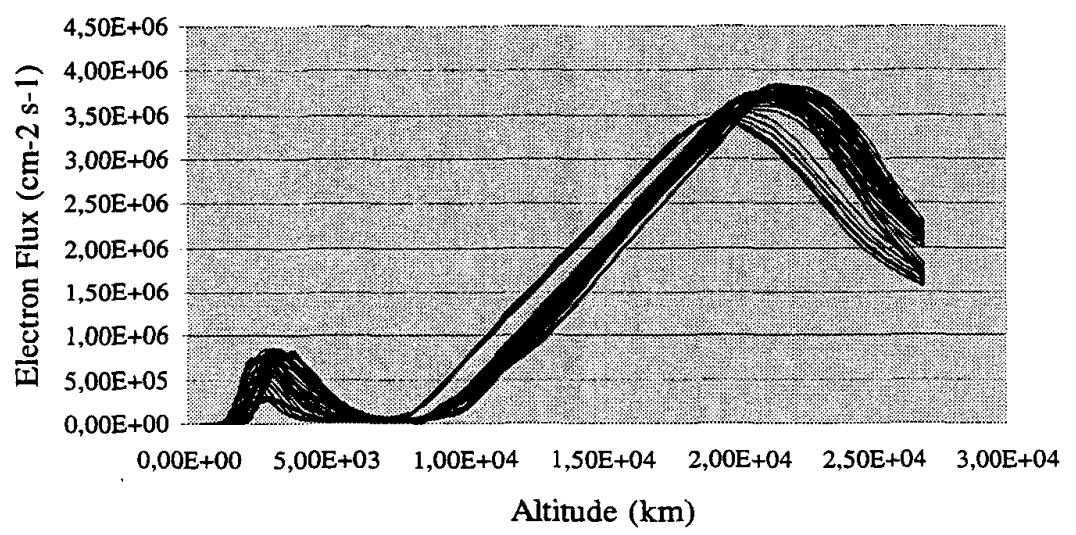

Figure 8: Trapped electron flux

4 PI Dose at centre of $\mathrm{Al}$ sphere for 1 orbit

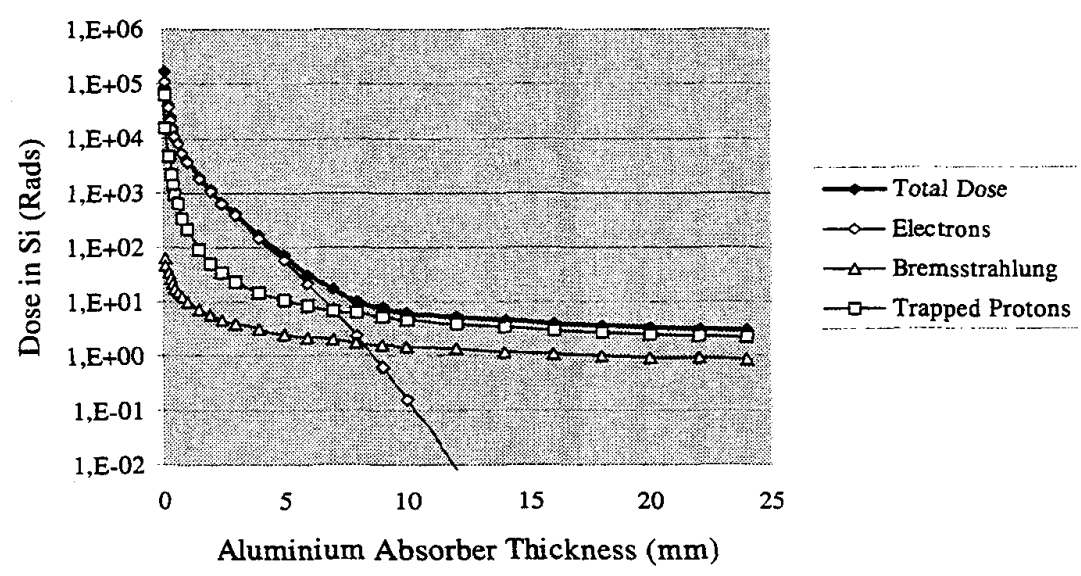

From the forward (viewing) direction, the bracket together with the lens provides for an effective equivalent shielding of $15 \mathrm{~mm}$ Al. From the sides, the CHU-box, which is made from Aluminum, provides for a shielding of $5 \mathrm{~mm} \mathrm{Al}$. The backside, however, was deliberately made so thin that the equivalent shielding is only $1.5 \mathrm{~mm} \mathrm{Al}$. Even though the massive MAQSAT-H reduces the view-factor considerably for heavy particles, the backscatter of especially electrons results in only a slight reduction in the view-factor for lighter particles.

\section{PlaNNED AND ACHIEVED ORBIT}

The Teamsat was planned to be launched into GTO, with a perigee of some $600 \mathrm{~km}$ and an apogee of $36.000 \mathrm{~km}$. The inner, trapped proton dominated Van Allen belt stretches from $1.200-10.000 \mathrm{~km}$.

The flux of trapped protons for the orbit of Teamsat is shown in figure 7 as a function of the altitude.

The Van Allen belts are far from being isotropic and vary especially with the local hour angle. Because the local hour angle of the perigee varies too, the actual dose rate experienced in each orbit varies too. This effect is evident from Figures 7 and 8 where the dose rate of each orbit in the mission is shown.

The outer, trapped electron dominated, Van Allen belt stretches from $10.000 \mathrm{~km}$ to $40.000 \mathrm{~km}$, as shown in figure 8. Hence, Teamsat was expected only to be in low radiation environment near perigee and near apogee.

The radiation dose-depth curve per orbit for the achieved orbit is shown in figure 9.

The intention was, to utilize the perigee passage to measure the cumulative dose effect on the CCD, and to utilize the low radiation environment when approaching the

Figure 9: Dose-depth for the Teamsat orbit 


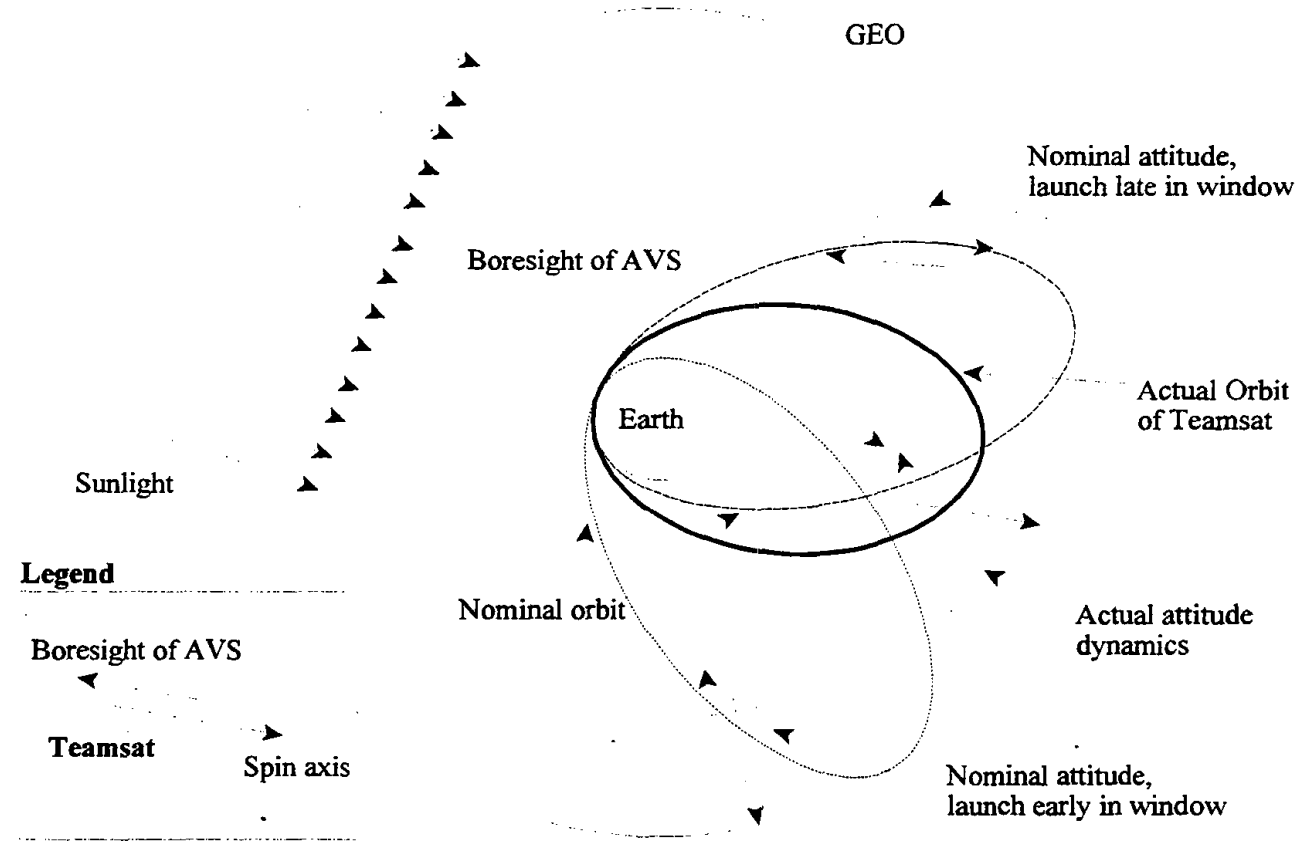

Figure 10: Planned and achieved orbits. Teamsat was launched quite late in the launch window.

apogee to test the autonomous non-stellar object detection and tracking function using the geostationary satellites as targets. Depending on the angle to the sun, the ASV is able to detect a geostationary satellite at about $10.000 \mathrm{~km}$ distance, i.e. prior to leaving the outer Van Allen belt.

The dynamic effects from energetic protons and electrons could then be studied parametrically when flying in the radiation belts.

The angle to the sun and the earth was quite critical due to the short baffle. The launch window for the Ariane 502 opened at 6.00 Kourou local time and closed again at 12.00. If Teamsat were launched early in the launch window, the nominal attitude-dynamics, which was controlled by the tip-off rate, would provide a comfortable margin to the Sun and to the Earth, for a large part of the orbit. The nominal orbits of an early and a late launch are depicted in figure 10. The figure also shows the actual orbit and attitude dynamics that was achieved.

From figure 10 it may be inferred, that the AVS actually was hampered in its operation for more than $75 \%$ of the time, due to sun blinding.

\section{LIFETIME DOSE ASSESSMENTS AND THE RADIATION EFFECTS}

Despite the quite high radiation flux levels experienced in GTO, due to the passing of the Van Allen belts, the mission dose for the DPU was a modest 220Rad. Figure 11 shows. DPU dose-rate versus time for an average orbit.

\section{DPU Irradiation for one orbit}

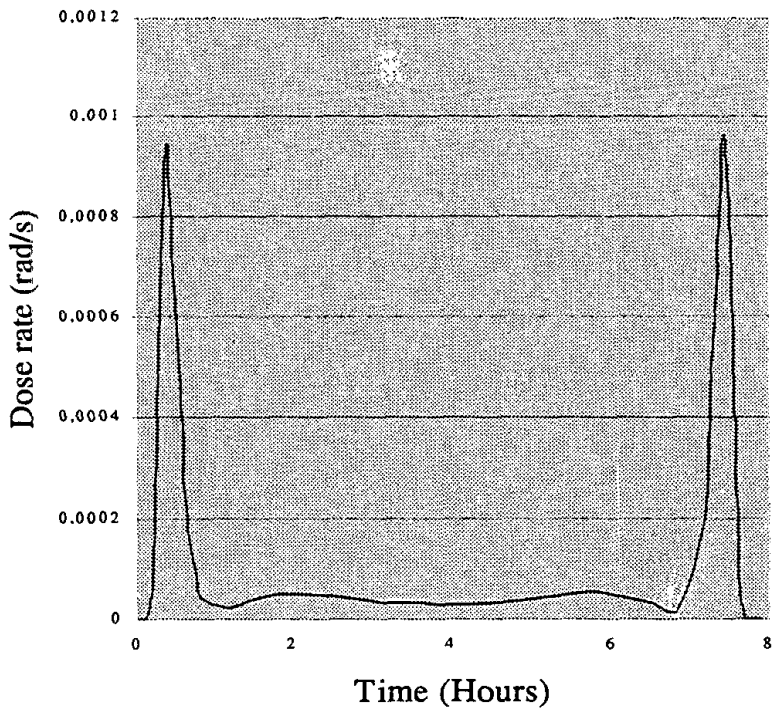

Figure 11: Accumulated DPU dose per orbit

The penetration of highly energetic trapped protons in the inner Van Allen belt is responsible for the two peaks (out-bound and in-bound passage respectively). As expected no effects from this dose was measured at all

The dose-rate versus time for the $\mathrm{CHU}$ is shown in figure 12 . 


\section{CHU Irradiation for one orbit}

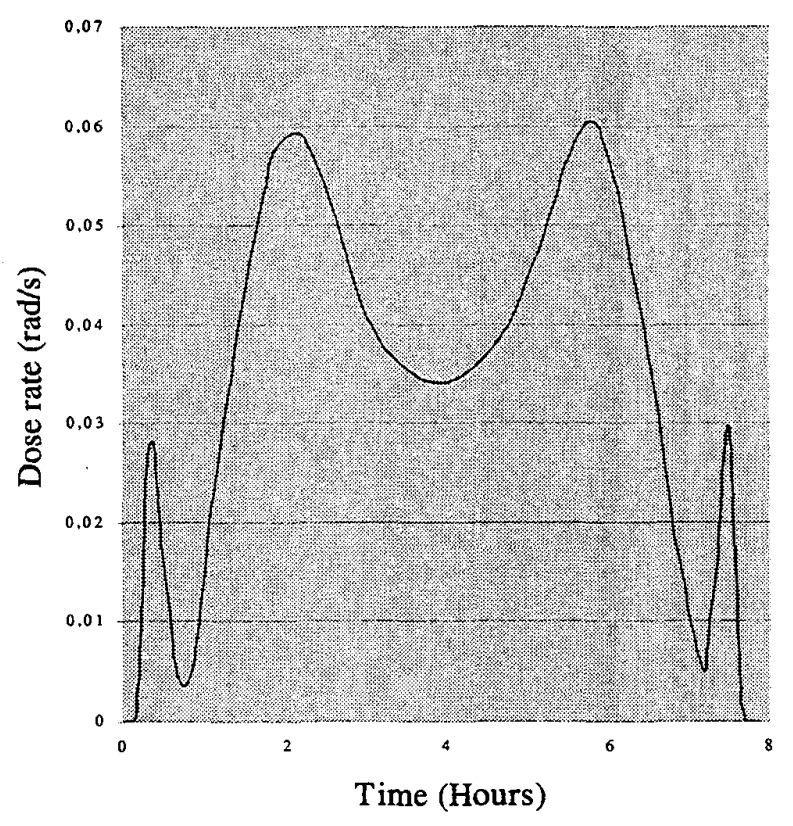

Figure 12: Accumulated CHU dose per orbit

This curve shows, as expected, a substantial dose received both per time and per orbit. The proton and electron belts generate the four peaks of the curve respectively. Please also note that by far the largest dose stems from energetic electrons. In table 2 , the calculated value of received dose per orbit is listed together with the corresponding average number of particles hitting the CCD per second.

As it is seen from table 2, the lifetime dose was quite high for a CCD-chip. However, by far the largest part of this dose originates from the electrons that result in only minor changes in certain parameters of the $\mathrm{CDD}$ as slightly increased dark-current and slightly increased non-uniformity of the chip.

Table 2: Dose composition and particle rates to the $C C D$, (calculated values).

\begin{tabular}{|l|l|l|l|}
\hline & $\begin{array}{l}\text { Dose/Orbit } \\
\text { (RAD) }\end{array}$ & $\begin{array}{l}\text { Number/sec } \\
\text { to CCD }\end{array}$ & $\begin{array}{l}\text { Lifetime } \\
\text { dose (RAD) }\end{array}$ \\
\hline Protons & 37 & 1,800 & 780 \\
\hline Electrons & 630 & 900,000 & 13.000 \\
\hline $\begin{array}{l}\text { Brems- } \\
\text { strahlung }\end{array}$ & 4 & N/A & 80 \\
\hline Total & 671 & 4.610 & 14.000 \\
\hline
\end{tabular}

Only the protons will give rise to substantial semi-permanent damage of the CCD-chip. Approximately 1 out of every
200.000 protons passing the CCD will generate a so-called hot spot, i.e. a pixel with increased sensitivity. The majority (95\%) of these damages vanishes after 24 hours, and already after one hour approximately a $60 \%$ reduction is seen. Hence, the number of hot spots generated per orbit should be approximately 60 . This number was verified from several images acquired throughout the mission. An image acquired after approximately 3 hours is shown in figure 13 .

The prominent grey band across the image was caused by transmission loss of data. Transmission loss of data was a problem in the early mission phases due to the poor link quality caused by the tumbling space-craft.

The bright spot in the upper right corner is the Earth partly in the field of view, and the bright spot to the left is a part of the launcher or MAQSAT-B.

The stars appears as oblong objects due to the high tumbling rate but the image are also showing several hot spots. Approximately 80 hot spots of various size may be detected. However, as the image was acquired close to the apogee, the electron flux was considerable, and comparing this image to the one acquired one second later proved that only some 14 are hot-spots candidates. This is close to the expected number of approximately 10 .

\section{DYNAMIC EFFECTS FROM RADIATION}

Table 2 also demonstrates an effect that, so far, has been overlooked in many star-tracker designs. Even though the number of particles creating permanent damage to the chip is quite low, each particle passing the $C C D$ will give rise to a substantial charge in the pixel traversed.

The actual charge generated depends on the particle type, energy and incidence angle. Protons passing in angles less than $60 \mathrm{E}$ will typically generate a charge in a pixel comparable to that of a star. Of the electrons approximately $10 \%$ will generate a charge in a few pixels comparable to that of a faint $\operatorname{star}(<\mathrm{mv} 4)$.

From these values and from the particle count values of table 2 it may be seen that some $20-50$ star like objects must be expected in each image, when flying in the proton dominated Van Allen belt. Similarly, the number of electrons, when flying in the electron-dominated Van Allen belt, is from 300 to 1000 star-like objects.

It is important to note that these star-like objects only persist in any specific pixel for a single image, already in the next image the effect of that specific particle has vanished, however new particles passing the $C C D$ have created new ones in other pixels.

As an example of these effects an image acquired in the electron-dominated region is shown in figure 14 .

These false star-like objects, i.e. dynamic effects from the radiation, will create far larger problems for star trackers flying in regions with large radiation fluxes. Overlooking this effect, especially from electrons, normally considered to be relatively benign, may lead to sub-marginal designs of the necessary shielding of the CCD. This is even more true, because most star trackers have an automatic detection and 


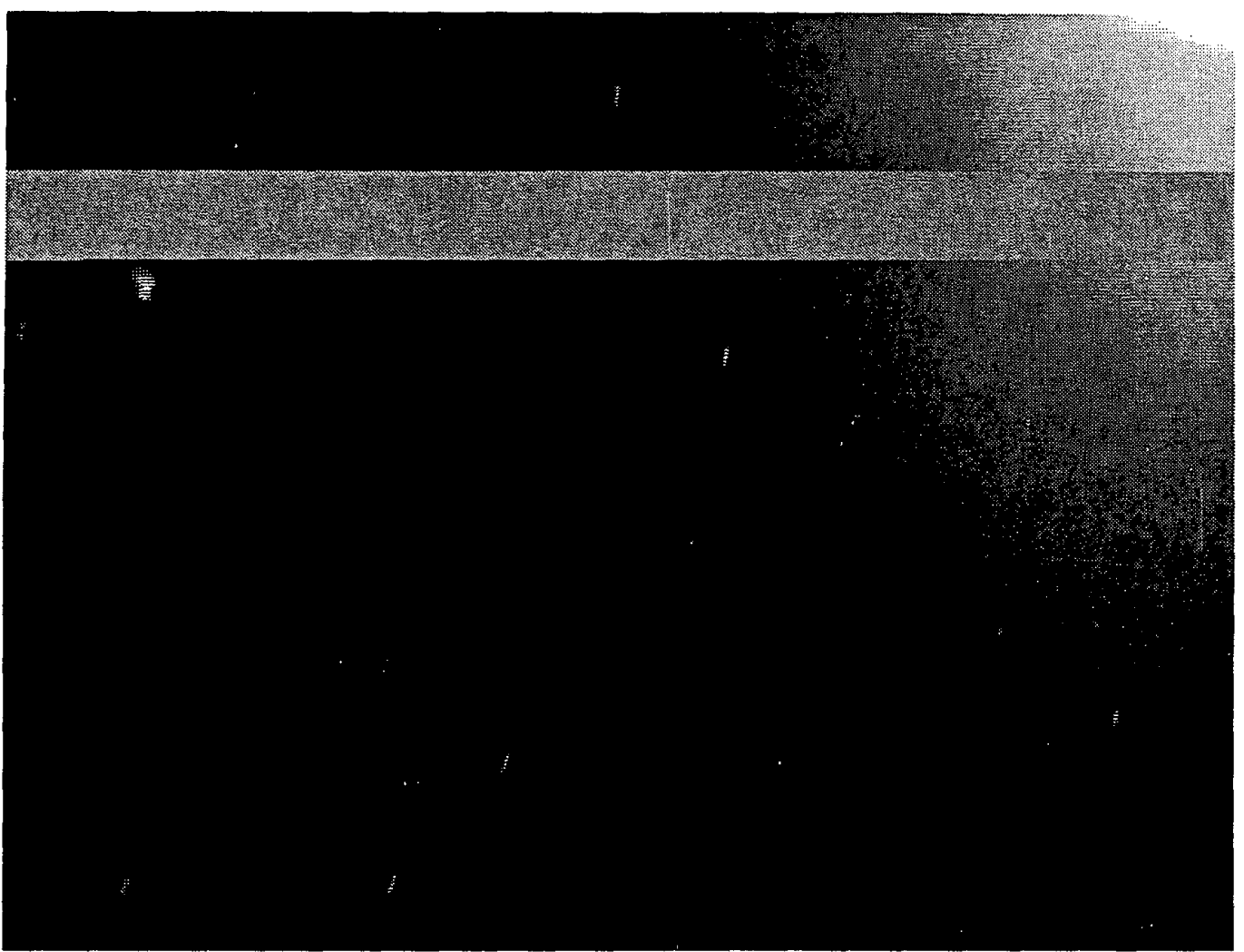

Figure 13: Image acquired after 1. passage of the proton dominated Van Allan belt

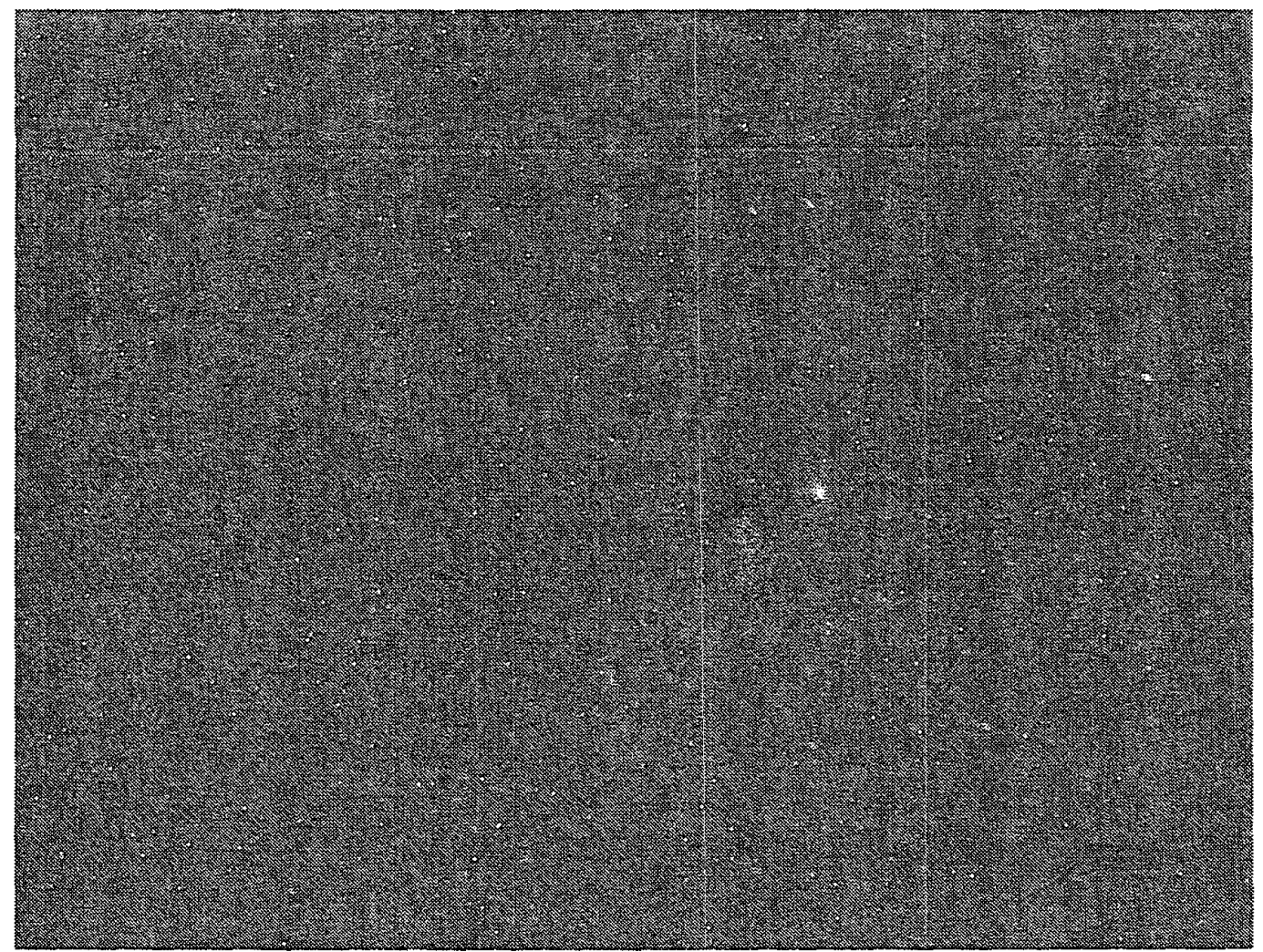

Figure 14: An image acquired in the electron dominated Van Allen belt after several orbits. 
tracking of the dark-level of the chip, and because the dynamic radiation effects may offset this tracking. A false measurement of a high dark-level will lead to loss of, at least, fainter stars, and will at best increase the noise equivalent angle.

\section{RAD-EFFECTS WORK AROUND AND APPLICABILITY}

Traditionally, the static damages, hot spots, are coped with by means of maintaining a hot-spot database. The list of centroids from an image is compared to the hot-spot database and all matches are removed.

The hot-spot database itself is regularly updated by comparing several images from different portions of the firmament. Any object common to all images (stars will vary with attitude) is then added to the database. And an object in the database, no longer detectable in the images is removed.

The comparison between a centroid list and the database is simple and may be performed real-time in space, however, the update of the database is not straightforward, and may pr ve to be difficult to perform, especially in spacecraft that requires stable attitudes for long periods of time.

The easiest work around of the dynamic radiation effects for missions with relatively low attitude change-rates, are simply to compare each centroid list to the previous list. All centroids that are not approximately common to the two lists are deleted. In this way, only centroids that have not moved far between two images are maintained for further processing. This method was used in the Teamsat data with a success-rate of $94 \%$, even in the region with the highest electron-flux. Typically only a few false star-like objects out of 150-180 were not removed by this filtering.

It is important to note, that using the intensity or the shape of the false objects is quite inefficient, as the intensity is approximately as that of a fainter star, and as the shape may be comparable to the one of a real star. This is especially true for the electrons, where any shape from single pixels, over stripes to almost perfect gauss-shapes has been observed.

\section{CONCLUSION}

The Teamsat platform, the achieved orbit and the tumbling type attitude motion provided an excellent platform for testing the autonomy and robustness of the star tracker operation and to non-stellar objects detection and tracking function of the Autonomous Vision System.

The major part of the orbit of Teamsat was inside the radiation belts due to an anomaly in the first stage of the launcher. The result was a high dose-rate for almost all the time, which in turn precluded a systematic assessment of the accuracy degradation vs. dose.

However, the same high dose-rate provided an excellent testbed for autonomous and robust star tracker operation in a high dose environment.

The AVS was able to efficiently handle the high dose-rate, dynamic as well as static, with only a moderate degradation in accuracy.
The test of the AVS onboard Teamsat highlighted that the dynamic effects from radiation often will prove to be a greater problem than the static effects. This is especially true in a trapped electron dominated environment.

\section{REFERENCES}

[1] M. Jones, B. Melton, M. Bandecchi, "TeamSat's low-cost egse and mission control system," ESA bulletin 95, Aug. 1998.

[2] J.L. Jørgensen, C.C. Liebe, "The Advanced Stellar Compass, Development and Operations," Acta Astronautica, Vol.39, Nov-Dec. 1996.

[3] J.L. Jørgensen, A.J. Pickles, "Fast and robust tracking using a second-generation star tracker". SPIE Vol. 3351 p51-61,1998.

\section{BIOGRAPHY}

John L. Jørgensen is a professor at the department of Automation at the Technical University of Denmark (DTU), where he is head of the Space Instrumentation Group (SIG) that developed the AVS. He has a MSc in Engineering and a $\mathrm{HD}$ in business and administration. His main research activities are robust vision systems, star trackers and vision in space.

Maurizio Betto is currently a Ph.D. student at the Technical University of Denmark (DTU) in the Space Instrumentation Group (SIG) working on the navigation function of the AVS. He has a MSc in Astronomy and worked seven years at the European Space Agency in the field of the guidance navigation and control.
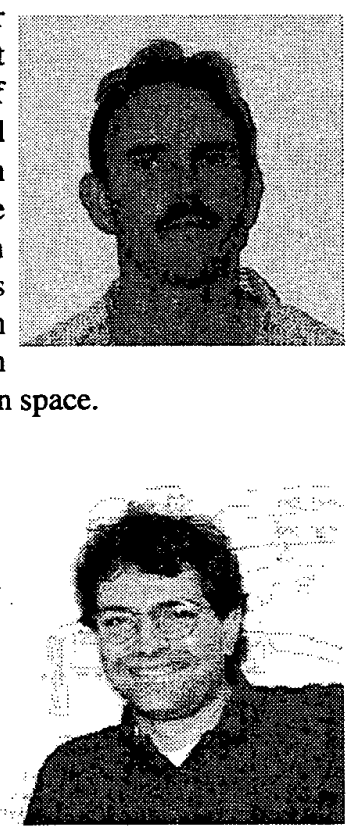

Troels Riis is currently a Ph.D. student at the Technical University of Denmark (DTU) in the Space Instrumentation Group (SIG). He has a MSc in Engineering. $\mathrm{He}$ is mainly doing research in the areas of non-stellar object detection and tracking, and pattern recognition for the AVS.

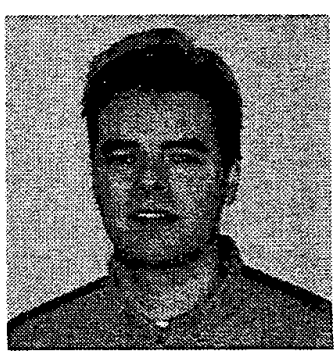

